\title{
THE EFFECT OF HEALTH LITERACY ON SELF-EFFICACY AND QUALITY OF LIFE: CANCER PATIENTS
}

\author{
A. Ozkaraman*, F. Uzgor*, O. Dugum**, S. Peker**.
}

*Eskisehir Osmangazi University, Faculty of Health Sciences- Department of Nursing, Eskisehir, Turkey.

${ }^{* *}$ Private Umit Hospital, Medical Oncology Clinic, Eskisehir, Turkey.

\section{INTRODUCTION-OBJECTIVE}

It is valuable in preventing negative health outcomes that patients are knowledgeable in the management of cancer and that they reflect this knowledge into their care. This research was conducted to evaluate the effect of health literacy in cancer patients on selfefficacy and quality of life.

\section{METHODS}

This cross-sectional, descriptive study was conducted with 111 cancer patients who were monitored and treated at the policlinics and clinics of Medical Oncology in a hospital in Eskisehir. The data were collected by means of "Individual Presentation Form", "Health Literacy Questionnaire-European Union (HLS-EU)", "Self-Efficacy for Managing Chronic Disease Scale (SMCD)" and "European Organization for Research and Treatment of Cancer Quality of Life Scale (EORTC QLQ-C30). The data were presented as mean \pm standard deviation for continuous variables and frequency and percentages for categorical variables. Mann-Whitney-U, One-Way ANOVA and Kruskal-Wallis tests were used to compare sociodemographic variables and disease characteristics with HLS-EU-Q47, SEMCD and EORTC QLQ-C30 scores. Spearman correlation analysis was used to assess the relationship between HLS-EUQ47, SEMCD and EORTC QLQ-C30. In the analysis results, $p<0.005$ was considered significant.

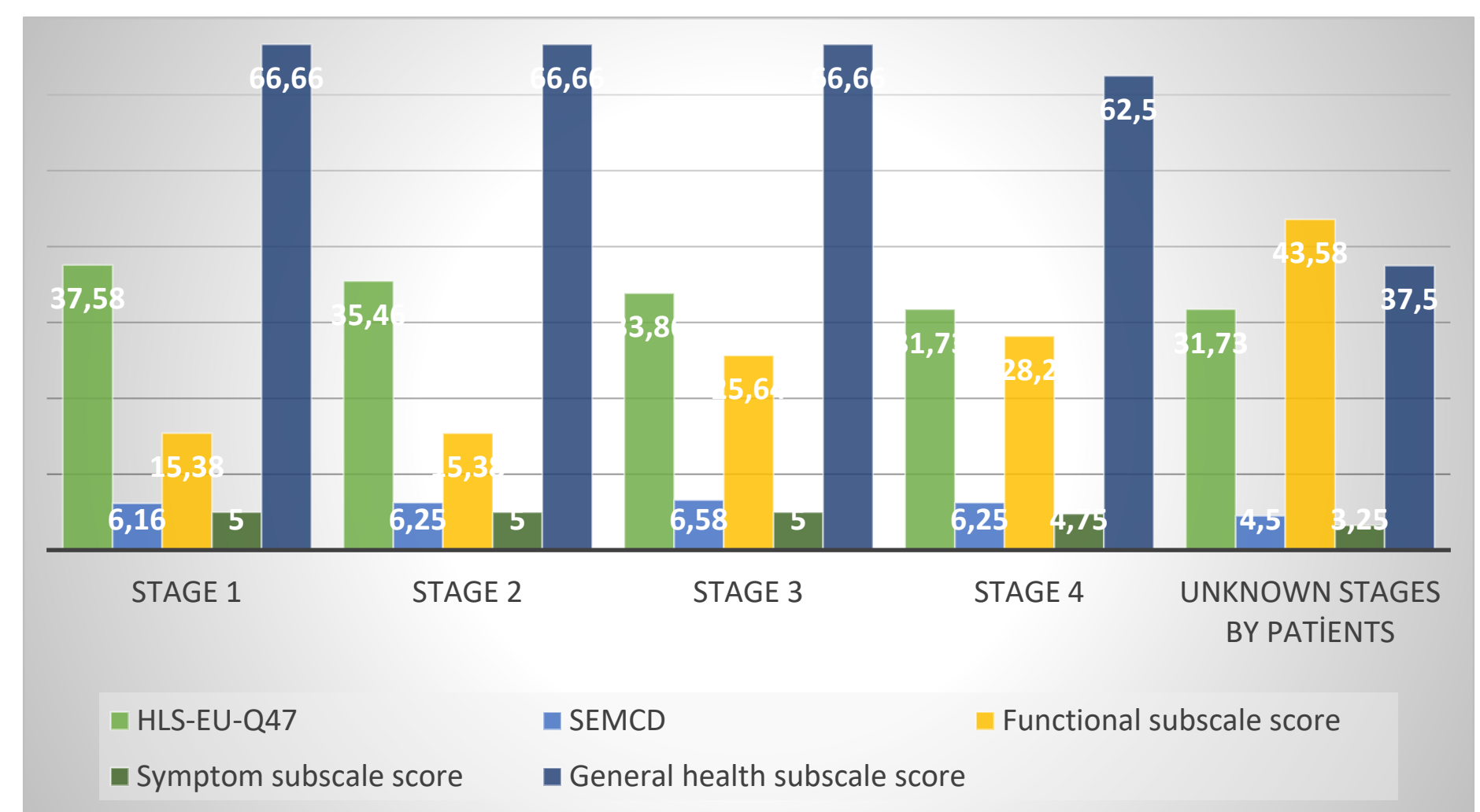

Graphic 1. HLS-EU-Q47, SEMCD and EORTC QLQ-C30 scales subscale scores according to stages o0f disease.

\section{DISCUSSION}

The results of studies on this field $(1,2,3)$ are similar to those of our study and as health literacy level of cancer patients and chronic disease management self efficacy score increase, general health status increases and disease symptoms decrease.
Table 1. Correlation between age, duration of disease, HLS-EU-Q47, SEMCD and EORTC QLQ-C30 subscales

\begin{tabular}{|c|c|c|c|c|c|c|c|c|}
\hline Characteristics & & 1 & 2 & 3 & 4 & 5 & 6 & 7 \\
\hline \multirow[t]{2}{*}{ 1. Age } & $r$ & & & & & & & \\
\hline & $\mathrm{p}$ & & & & & & & \\
\hline \multirow{2}{*}{$\begin{array}{l}\text { 2. Duration of } \\
\text { disease }\end{array}$} & $r$ & .135 & & & & & & \\
\hline & $\mathrm{p}$ & 0.157 & & & & & & \\
\hline \multirow{2}{*}{$\begin{array}{l}\text { 3. Frequency of } \\
\text { applying to the } \\
\text { health care } \\
\text { institution }\end{array}$} & $r$ & .062 & .012 & & & & & \\
\hline & $p$ & 0.517 & 0.901 & & & & & \\
\hline \multirow[t]{2}{*}{ 4. HLS-EU-Q47 } & $r$ & -.107 & -.130 & -.0184 & & & & \\
\hline & $p$ & 0.265 & 0.175 & 0.054 & & & & \\
\hline \multirow[t]{2}{*}{ 5. SEMCD } & r & .050 & .075 & -.0184 & .032 & & & \\
\hline & $p$ & 0.603 & 0.434 & 0.053 & 0.741 & & & \\
\hline \multirow{2}{*}{$\begin{array}{l}\text { 6. Functional } \\
\text { subscale score }\end{array}$} & r & .007 & -.131 & -.093 & .107 & .531 & & \\
\hline & $p$ & 0.844 & 0.170 & 0.332 & 0.262 & $<0.001$ & & \\
\hline \multirow{2}{*}{$\begin{array}{l}\text { 7. Symptom } \\
\text { subscale score }\end{array}$} & $r$ & -.080 & .077 & .066 & -.334 & -.382 & -.667 & \\
\hline & $p$ & 0.406 & 0.421 & 0.492 & $<0.001$ & $<0.001$ & $<0.001$ & \\
\hline \multirow{2}{*}{$\begin{array}{l}\text { 8. General Health } \\
\text { subscale score }\end{array}$} & $r$ & -.019 & .016 & -.084 & .199 & .411 & .264 & -.409 \\
\hline & $p$ & 0.845 & 0.879 & 0.383 & 0.036 & $<0.001$ & 0.005 & $<0.001$ \\
\hline
\end{tabular}

\section{RESULTS}

The mean age of 111 patients who participated in the study was $55.62 \pm 12.75$ years. Of the participants, $74.8 \%$ were female $(n=83), 56.8 \%$ were primary school graduates $(n=63)$ and $61.3 \%$ were diagnosed with breast cancer $(n=68)$. This study found that the HLS-EU-Q47, SEMCD and EORTC QLQ-C30 scores of patients did not differ by sociodemographic characteristics and cancer diagnoses ( $p>0.05$ ) (Graphic 1), but they showed statistically significant difference according to their stages of disease. This study also found a positive and significant relationship between the HLS-EU-Q47 score and the general health subscale score of the EORTC QLQ-C30 scale ( $r=0.199, p=0.036)$, and a negative and significant relationship with the symptom subscale score $(r=-0.334, p<0.01)$.

\section{REFERENCES}

1.Halverson JL,et al. Health literacy and health-related quality of life among a population-based sample of cancer patients. Journal of Health Communication International Perspectives, 2015;20(11).

2.Song, Lixin, et al. How does health literacy affect quality of life among men with newly diagnosed clinically localized prostate cancer? Cancer 2012 118(15): 3842-3851.

3.Wang et al. The Effect Of Health Literacy And Self-Management Efficacy On The Health Related Quality Of Life Of Hypertensive Patients In A Western Rural Area Of China:A Cross-Sectional Study. Journal for Equity in Health 2017;16(58):1-1 